\title{
J. MINAYA, PEDRO FRANCISCO BONÓ. VIDA, OBRA Y PENSAMIENTO CRÍTICO, SANTO DOMINGO, ARCHIVO GENERAL DE NACIÓN
}

\author{
Pablo Guadarrama González
}

Universidad Católica de Colombia

DOI:10.14718/CulturaLatinoam.2017.26.2.11

Cada vez que un investigador de la historia del pensamiento da a conocer una obra reveladora de la riqueza intelectual de algún digno representante del inagotable tesoro que constituye la producción de ideas en América Latina y el Caribe —y la consecuente actitud práctica de sus gestores-, no solo aporta una joya más a la cultura de esta región, sino también a la universal. ¿ $\mathrm{O}$ acaso se seguirá pensando que la patente de corso para navegar por la universalidad le está reservada exclusivamente a personalidades europeas?

Este es el caso del libro Pedro Francisco Bonó. Vida, obra y pensamiento crítico, de Julio Minaya, acucioso investigador que, en esta ocasión, presenta los resultados de una larga labor de búsqueda y revelación de las ideas y la praxis política, educativa y cultural de esta relevante personalidad de la cultura dominicana. Con los valiosos elementos de juicio que ofrece esta enjundiosa obra, no tiene por qué Bonó (1828-1906) esperar más para formar parte de la mejor tradición del pensamiento latinoamericano y universal.

El fundamentado criterio de que a Bonó «le cabe el mérito de ser el precursor de la emancipación mental y cultural del pueblo domini-

Referencia: Guadarrama, P. (2017). J. Minaya, Pedro Francisco Bonó. Vida, obra y pensamiento crítico, Santo Domingo, Archivo General de Nación. Cultura Latinoamericana. Revista de Estudios Interculturales. 26(2), pp. 251-258. DOI: 10.14718/CulturaLatinoam.2017.26.2.11 
cano» (Minaya, 2014, p. 136) -pues «llegó a convertirse en propiciador de la racionalidad crítica en la República Dominicana» (p. 22)- es razón suficiente para que su nombre figure junto al de Bello, Bilbao, Montalvo, Martí, Vasconcelos, Rodó, Hostos, Henríquez Ureña, y tantos otros que han contribuido a ese largo y tortuoso proceso de completamiento de la independencia política ${ }^{1}$ y de maduración de la identidad cultural latinoamericana.

Publicado por el Archivo General de la Nación de República Dominicana, en su volumen CCXV — por razones más que justificadas al constituir Bonó una de las figuras descollantes de esa nación caribeña-, el libro en sus más de cuatrocientas páginas posibilita una comprensión integral del ilustre pensador.

Ofrece en su primera parte un panorama de Latinoamérica durante el siglo XIX, recoge aportadoras reflexiones sobre las principales corrientes filosóficas, como el eclecticismo, el socialismo utópico y el krausismo, que antecedieron al positivismo, luego predominante en el ámbito latinoamericano (Guadarrama, 2004), y del cual Bonó se distanciaría de manera crítica, especialmente en su concepción del progreso ${ }^{2}$,

Lo cual tiene una explicación básica: su visión humanística estaba profundamente enraizada en los principios de justicia social, libertad, igualdad, felicidad y caridad, por lo que en ella no cabía un progreso que no incluyera los sectores sociales que integraban lo que el denominaba «el dominicano genuino» (Minaya, 2014, p. 134).

A esto se añade su «denuncia ecológica» (Minaya, 2014, p. 326) al criticar, con el auxilio de la perspectiva rousseauniana, la concepción del progreso concebido en términos del creciente industrialismo propiciado por el capitalismo, que, a juicio de Marx, por su naturaleza es hostil a la naturaleza. Lamentablemente la historia le ha dado la razón al pensador de Tréveris.

Existen motivos suficientes para coincidir con el autor en que:

[...] cuando se escriba la historia del proletariado dominicano y se refiera la defensa de las clases trabajadoras y de los sectores empobrecidos, ha-

1. «En su calidad de intelectual crítico, Bonó se convirtió en el principal vigilante y defensor de la emergente nación. Por doquiera contemplaba las trabas que dificultaban su avance hacia la institucionalidad democrática, hacia la instrucción de sus hijos y el bienestar de las "clases inferiores"》 (Minaya, 2014, p. 194).

2. «Por supuesto, al colocar en tela de juicio la noción liberal-positivista del progreso, Bonó está cuestionando una de las categorías centrales de la modernidad occidental y de la Ilustración» (Minaya, 2014, p. 27). 
brán de colocarse las figuras de Bonó y Ulises Francisco Espaillant en un lugar especial: ambos se pronunciaron tempranamente -1875- a favor de un aumento de sus salarios (Minaya, 2014, p. 141).

Minaya (2014) acentúa dos aspectos muy significativos en la labor de Bonó:

Es cierto que ya se empleaba el gentilicio de dominicano y que se habían adoptado los símbolos patrios, pero subjetiva y mentalmente se continuaba siendo español. Bonó es el primero en República Dominicana que descubre ese tipo -sutil si se quiere- de dependencia. Luchar contra ella constituía la premisa necesaria de todo esfuerzo enderezado a la consecución del Estado-nación (p. 139).

Pero en tal sentido su labor no resultó suficiente, sino que «fue el primero que abogó por la emancipación económica de la República Dominicana» (Minaya, 2014, p. 140). También en esta primera parte analiza con detenimiento los aportes del romanticismo, el costumbrismo y el realismo para forjar la identidad hispanoamericana.

En su segunda parte, el libro presenta una pormenorizada biografía intelectual y política de Bonó. En ella destacan algunas doctrinas que influyeron en su pensamiento, como el socialismo utópico y el humanismo católico (Minaya, 2014). Dada su profunda preocupación por la situación de los obreros, Minaya sostiene: «En ese sentido es cierto que Bonó realizó análisis que guardan cierta similitud con planteamientos marxistas» (p. 146). Aunque se debe tener presente que no solo el marxismo expresaba tales preocupaciones, pues también lo harían otras corrientes socialistas y anarquistas.

Ahora bien, esto no es lo importante, en cuanto a sus posibles aproximaciones a la ideología socialista, lo significativo es que, dada su postura liberal y su identificación con los sectores humildes de la población, fue perseguido por los sectores conservadores y se vio obligado a emigrar a Estados Unidos. Indudablemente, su pensamiento y su actitud política resultaban peligrosos para aquellos sectores oligárquicos que querían mantenerse en el poder y les preocupaba que el pueblo dominicano cultivase su emancipación mental y cultural, como la promovía Bonó ${ }^{3}$, porque esto podía conducir, como en todas partes, a movimientos sociales mucho más radicales ${ }^{4}$.

3. «Bonó no cejó en el esfuerzo por fomentar el hábito de pensar y de hablar libremente sobre los problemas nacionales en el ámbito público» (Minaya, 2014, p. 221).

4. «Fue, en efecto, un abanderado de la justicia social, un defensor de la dignidad y de los derechos de la persona humana» (Minaya, 2014, p. 325). 
En esta parte del libro se detiene en algunas de las significativas polémicas en que participó Bonó y se aprecian sus francas posiciones ideológicas progresistas, las cuales enriquecieron la vida cultural y política dominicana de la época.

Minaya (2014) se enfrenta a los criterios de algunos que consideran al ilustre dominicano como un pesimista, por no comprenderlo «en ocasiones, agobiado por las circunstancias adversas padecidas por la nación, frente a las que se sentía impotente» (p. 154), pues con su prudente postura trataba siempre de evitar los excesos y buscar el término medio en las confrontaciones. Y por esas razones el autor lo califica «más bien de realista crítico» (p. 153) con «proclividad al reflexionar filosófico»(p. 183). Tal postura conciliadora -ya que «Conforme se aproximaba al ocaso de su vida, Bonó fue inclinándose cada vez más hacia un sentido cristiano de la existencia» (Minaya, 2014, p. 183)- le hace asumir:

[Un] punto de equilibrio: ni únicamente ciencia, como concibe el positivismo, que rechaza toda construcción metafísico-espiritual; pero tampoco únicamente la religión, que pretende prescindir de la explicación científica. A su juicio se requieren los aportes de cada una de estas instancias para lograr alcanzar una orientación vital adecuada que dé cuenta del sentido espiritual de la existencia humana (Minaya, 2014, pp. 180-181).

De tal modo, Bono se incluye en esa generación antipositivista que emergió entre numerosos pensadores latinoamericanos de fines del siglo XIX y que buscaban en un nuevo idealismo, como pensaba Rodó, un asidero teórico mejor para la comprensión de la condición humanas.

Finalmente, en la tercera parte se profundiza en el pensamiento de Bonó y su valioso papel como precursor de la emancipación cultural dominicana, aun cuando, tal como ocurrió con otros pensadores latinoamericanos de su época, no haya sometido a severa crítica la escolástica -«si bien se refirió a dicha vertiente teórica como una filosofía no sana» (Minaya, 2014, pp. 324-325)-, debido, según Minaya, a su formación autodidacta. A su juicio:

Puede afirmarse que tanto la corriente romántica como la costumbrista contribuyeron de manera decisiva para que Bonó y sus homólogos latinoamerica-

5. Véase: Guadarrama (2003), Proyecto Internacional de Investigación «El pensamiento latinoamericano del siglo xx ante la condición humana», disponible en www.ensayistas.org/ critica/generales/C-H/. 
nos fijaran la mirada en sus respectivos terruños y reivindicaran los modos de vida de los sectores que más hondamente habían arraigado en estos (p. 201).

Analiza su papel como primer impugnador de la mentalidad colonial dominicana, aunque lo más significativo es que Minaya (2014) desentraña la razón por la que «a Bonó hay que acreditarlo como uno de los próceres de la emancipación política del país frente al poder ibérico. Pero además le cabe legítimamente el título de precursor de la emancipación mental nacional» (p. 222). La causa de tal duplicidad la encuentra de manera muy acertada en la formación filosófica y política moderna, que le impidió dejarse atrapar ideológicamente por aquellas ideas que habían fundamentado el poder colonial. Un mérito que se añade a tal postura anticolonialista es que logra «captar el neocolonialismo y la presencia imperial de Estados Unidos durante el período finisecular del siglo XIX» (p. 325).

Ahora bien, Minaya (2014) elogia el hecho de que Bonó haya sabido valorar a la vez algunos elementos favorables en la colonización española, «como la hospitalidad, la ausencia de odios raciales y el cosmopolitismo» (p. 324), que propiciaron el profundo mestizaje -a diferencia de la colonización francesa en Haití-, del cual ha sido producto el pueblo dominicano.

Resulta meritoria la consideración del autor cuando plantea que:

No estamos ante un filósofo típicamente ilustrado: Bonó no llegó a proponérselo y resulta a todas luces imposible exigírselo. Más bien se trata de un pensador hispanoamericano que pudo hacerse de una formación autodidacta gracias a la lectura de libros de derecho y de obras clásicas cuyos núcleos conceptuales asimiló y adaptó a su propio quehacer a favor de la sociedad dominicana (Minaya, 2014, p. 214).

Debidamente aclara que «adaptó», pues no se trata de que «adoptó». Este ha sido, y aún es, uno de los temas cruciales que desde hace muchos años preocupa a defensores y críticos de la existencia de una producción filosófica latinoamericana.

Es muy común encontrar en estudios al respecto que se haga referencia a la «recepción» de algún filósofo europeo entre los cultivadores de dicha disciplina en esta región, con lo que se limita la actividad intelectual de estos últimos a la función de receptores, como en el béisbol, pero nunca como lanzadores.

Una perspectiva metodológica sesgada de esa forma tampoco es capaz de comprender que Mencio no adoptó a Confucio, ni Plotino 
o Séneca adoptaron a Platón, del mismo modo que Tomás de Aquino tampoco adoptó a Aristóteles, o Spinoza a Descartes, Kant a Hume, Montesquieu a Locke, Marx a Hegel, James a Stuart Mill, Heidegger a Nietzsche, Bello a Berkeley, Varona a Spencer, Mariátegui a Marx, etc., sino que los adaptaron a sus propias reflexiones circunstanciales y auténticas, independientemente de su mayor o menor originalidad ${ }^{6}$. Así ha sucedido siempre en la historia del pensamiento en todas las épocas y latitudes, y así seguirá siendo. Lo mismo hizo Bonó, valoró de sobremanera numerosas ideas de diversas fuentes ${ }^{7}$, pero ante todo pensó con cabeza propia ${ }^{8}$-y con su ejemplo personal y la promoción de una educación adecuada propició que su pueblo lo imitara-, con los pies puestos en su tierra y el corazón en su pueblo.

Minaya no se plantea en su libro demostrar que Bonó fue un pensador original, sino auténtico, que es más importante que lo primero, porque utilizó los mejores instrumentos filosóficos del pensamiento moderno a los cuales tenía acceso en sus circunstancias no para simplemente contemplarlas o interpretarlas teoréticamente, sino para orientar su crítica y práctica transformación, en especial propiciando la instrucción pública favorecedora de los sectores populares ${ }^{10}$.

Aunque tal vez haya pensado al final de su vida, como pensó Bolívar, que había arado en el mar, en verdad no fue así. Ambos, en planos y perspectivas muy diferentes, ayudaron de manera significativa, y no con simples granos de arena, a que el pasado ${ }^{11}$ no se perpetuara en Latinoamérica.

6. «El grado de autenticidad no debe ser confundido con formas de originalidad, pues lo determinante en la valoración de un acontecimiento cultural no es tanto su novedad o irrepetibilidad, sino su plena validez» (Guadarrama, 2009, p. 58).

7. «Bonó no fue un autor que siguiera a pie juntilla fórmulas o definiciones ajenas, elaboró sus propias conceptualizaciones obedeciendo a criterios personales. Tampoco tuvo la inclinación del maestro que se dedica a enseñar; encarnó más bien al intelectual ético-crítico que busca el sentido y las explicaciones de los problemas que angustian al conglomerado social» (Minaya, 2014, p. 228.).

8. «El pensar era para Bonó un medio de procurar solución a los problemas, fueran estos de orden práctico o teórico» (Minaya, 2014, p. 218).

9. «[...] Bonó deja sentado en el país el pensamiento crítico, uno de los atributos fundamentales de la civilización occidental» (Minaya, 2014, p. 323).

10. «Bonó tenía la firme opinión de que erradicando del país la "la lepra terrible de la ignorancia" se lograría alejar para siempre las convulsiones terribles que agitaban en todo momento a la joven nación» (Minaya, 2014, p. 269).

11. «Fue así que criticó el pasado colonial y el republicano, puso en tela de juicio la sociedad en que vivió, cuestionó las actuaciones de los gobiernos, puso de manifiesto los vicios de la élite y denunció la inclinación voraz y explotadora del capital extranjero» (Minaya, 2014, p. 215). 
La investigación realizada por Minaya contribuye notablemente a reivindicar esta cimera personalidad ${ }^{12}$, no solo para el pueblo dominicano -que la desconoce-, sino para el resto de los latinoamericanos, pues, como sugiriera José Martí, han de conocerse porque han de luchar juntos. No por conocida deja de ser lamentable la idea según la cual un pueblo que desconoce su historia está condenado a repetirla. Por supuesto que existen muchos poderes que tratan de inculcar la idea de que los pueblos dejen de cultivar su pasado, porque son evidentes las intenciones fagocitósicas que esconden tales tesis.

Confieso que era muy superficial el conocimiento que tenía del pensamiento y la actitud política de Bonó. Este libro me ha permitido confirmar mi criterio de que en América Latina el humanismo práctico ha sido consustancial a las mejores expresiones de sus más dignos representantes del pensamiento y la praxis política. El ilustre dominicano no constituye una excepción, sino que confirma la regla.

El libro está escrito con un lenguaje que, sin dejar de ser profundamente académico, es claro y apropiado para cualquier lector que al menos haya cultivado la educación superior. Permite una adecuada comprensión y valoración de está destacada personalidad del pensamiento y la praxis política de Nuestra América, que supo cultivar las letras de manera tal que no quedasen solamente impresas en los libros, sino que se convirtieran en trincheras de lucha por la emancipación mental, cultural y política no solo de los dominicanos, sino de todos aquellos que aún pueden encontrar en sus obras y su ejemplo personal un referente paradigmático para seguir enriqueciendo la cultura latinoamericana y, por qué no, también la universal.

\section{Referencias}

Guadarrama, P. (2003). Proyecto Internacional de Investigación «El pensamiento latinoamericano del siglo XX ante la condición humana». Recuperado de www.ensayistas.org/critica/generales/C-H/. Guadarrama (2004). Positivismo y antipositivismo en América Latina. La Habana: Editorial Ciencias Sociales. Recuperado de http://biblioteca.filosofia.cu/php/export.php?format $=$ htm\&id=231\&view $=1$.

12. «Lo que ocurre es que Bonó es prácticamente desconocido por el pueblo dominicano, lo cual es expresión palmaria de la ausencia de una tradición intelectual que recoja los aportes fundamentales de los autores que más se han preocupado por pensar el país y sus problemas» (Minaya, 2014, p. 207). 
Guadarrama, P. (2009). Autenticidad. En H. E. Biagini \& A. A. Roig (Dir.), Diccionario del pensamiento alternativo (p. 58). Buenos Aires: UBA.

Minaya, J. (2014). Pedro Francisco Bonó: vida, obra y pensamiento crítico. Archivo General de la Nación, vol. CcXv. Santo Domingo: Editora Centenario. 